\title{
(Re)Imagining Teacher Preparation for Conjoint Democratic Inquiry in Complex Classroom Ecologies
}

DEBORAH L. SELTZER-KELLY, Southern Illinois University, Carbondale (USA)

SERINA CINNAMON, Southern Illinois University, Carbondale (USA)

CRAIG A. CUNNINGHAM, National-Louis University (USA)

SUZANNE T. GURLAND, Middlebury College (USA)

KALINDA JONES, Indiana State University (USA)

SHANNON LINDSAY TOTH, Southern Illinois University, Carbondale (USA)

\begin{abstract}
In this article, we discuss the idea that, in a genuinely pluralistic and egalitarian society that values the growth and development of the individual as an essential part of the educational process, teachers must be prepared to come into relationship with students who may represent the philosophical Other. Notions of deviance and pathology can infuse diverse classrooms when rigidly standardized curricula are implemented by teachers who are trained only as technicians, and who may view the students and their families and communities as the locus of blame if students are unable to achieve. Preparing teachers for these complex interactions requires that teacher educators attend to qualities that go far beyond usual constructions of content/pedagogical competence and professionalism. We explore these issues through the lens of complexity, bringing to the conversation the scholarship of a range of theorists and disciplines including great historic figures such as John Dewey, Gregory Bateson and Martin Buber, as well as contemporary theorists including James Hillman.
\end{abstract}




\section{Introduction}

As a student, Shannon was quickly labeled as a "smart kid" - one for whom success in school came easily. Her experiences also left her somewhat cynical, however; she noticed differences between her own experiences and those of her peers who were not considered gifted. She entered the teaching profession with a deep commitment to social justice and a focus upon becoming a different kind of educator:

I wanted to be a teacher who knew and valued her students for the people that they were, rather than for the grown-ups they might become one day. I was strongly focused on justice-on the ways in which schooling let kids down. I was also idealistic about my own power in the classroom; as an elementary school teacher, I hoped that high expectations and enthusiasm could head off feelings of disappointment and indifference before my students reached high school.

The reality of the conditions faced by my students truly did not match the theories I had learned. I was quickly warned not to eat snacks that came from certain kids' houses, as their families were understood to be dirty. I had fifth graders who smelled of urine daily, and were rumored to sleep in a barn. Gifted children were not able to participate in supplemental programs because of financial problems. First graders were under the impression that other kids didn't like them because they were black. Several children had already given up on school in general and on themselves specifically. I, however, was expected to write lesson plans, teach the material, and try not to be too incendiary with regard to the ideas I had hoped to discuss.

Serina, like Shannon, had been a highly successful student. She also, like Shannon, had a strong commitment to social justice and educational equity, but her classroom experiences as a new teacher came as a substantial shock:

I found myself teaching students with horrendous test scores, abominable behavior, and attitudes that seemed lackadaisical to say the least; they were considered "the lowest of the low." Some days it was all I could do to keep order, let alone teach anything of value. My students did not seem very interested in anything that was happening at the front of the classroom; they resisted work of any kind and questioned everything. Perhaps the worst challenge was watching these students consistently make choices that closed academic doors to them.

Based upon what I knew and understood at the time, I felt there could only be one of two conclusions; it was either the students or the system. I had already witnessed colleagues arriving at the former conclusion. These teachers were determined to "stick to their principles" and refused to "dumb down" their curriculum. Every conversation held the status quo sacrosanct.

But how could it be the system? I also respected authority and had significant "buy in" to the system. My father was a military instructor who ran the home like he ran his training classroom. From this I came to understand and internalize ideas about chain of command, obeying authority, and following orders. I also understood the rules of the game: compliance coupled with excellence gained one favor and while there was no "beating the system," one could maneuver and manipulate it effectively if only one understood the rules. By the time I exited the K-12 system, two notions were firmly entrenched: 1) the system worked; and 2) people got what they deserved or earned.

Clearly, there is an elephant in the collective living room of our sphere of public education. Despite the rhetoric of egalitarianism and meritocracy that pervades the system of public education, teachers and their students are often separated by a gap far 
larger than obvious issues of age and respective educational attainment: there is a chasm of socioecononic class and culture, with accompanying differences in experiences and expectations. As we can see from Shannon's and Serina's accounts, too, ensuring that prospective teachers have a deep commitment to educational equity is not enough. We must prepare teachers to step out of the cycle of blame-the effort to assign deficits to children, teachers, schools, and communities. Rather, the scholarship that we examine here suggests that we must seek new insights and alternative approaches through the incorporation of a complexity perspective.

\section{Our Method(s) and Lens(es)}

The authors of this paper, drawn from a range of educational fields and bringing a diversity of classroom experiences, came together to examine and discuss the issue of classroom relationships at a symposium at the 2010 annual meeting and conference of the American Educational Research Association. This paper follows and expands upon the portions of our respective papers presented at that session, and additionally incorporates many conversations that took place before, during and after that presentation.

The work of Gregory Bateson became the lens for our discussions-in particular, a segment of Nora Bateson's (2009) film "An Ecology of Mind" framed our considerations. The viewer sees Mary Catherine Bateson reflecting upon a videotaped family counseling session that she has watched repeatedly as part of her professional supervision of the counselor. The designated client is the child, who has been identified as having behavioral issues. However, over repeated viewings of the session, Bateson has found that her perspective as to the actual source of the problem has shifted several times. She began by seeing the child as the sole possessor of issues. She then moved toward considering the mother as the precipitating factor, then the father, and finally, after many viewings of the interactions in the session, has begun to wonder whether the therapist is fomenting dysfunction. Finally, she explains, she has come to view the family dynamic in terms of Gregory Bateson's thought: to see the pathology as a product of the interaction of systems, rather than as residing in any individual.

Embracing a complexity-based model-particularly the Batesonian focus upon the interaction of systems-this work weaves together deeply qualitative and autoethnographic approaches with quantitative empirical studies and philosophic theorization. We embrace this multiplicity because we believe that "complexity discourse is not a metadiscourse that seeks to offer totalized explanations, but an umbrella notion that enables researchers to note profound similarities across a diversity of phenomena" (Davis \& Sumara, 2006, p. 127). In this way, we work to embody complexity not only in our thinking about the subject of our inquiry, but in our mode of inquiry.

The structure of this piece seeks to preserve the richness and variety of the multiple voices and traditions that were heard within our individual writings, presentations at the symposium, and the discussions that preceded and followed. Much of what is 
contained here is drawn directly from our original papers, and thus reflects the discourses of our individual fields. Debbie, the symposium organizer and first author, has "written around" these individual works, seeking to draw them together and highlight some connections, while showcasing their individuality. In taking this approach, we follow Macbeth's (2001) advocacy for "positional reflexivity" as a research exercise that "rather than 'leveling' the world with a singular, objectivizing narrative voice, $[\ldots]$ preserves and recovers the polysemy of multiple positions, interests, and agencies in the settings it analyzes" (p.39). In this, we knowingly "breach canonical conventions and expectations" (Bochner, 1997, p. 434) and "give up the illusions of transcendental observation in favor of the possibilities of dialogue and collaboration" (p. 435). Thus, our individual voices are allowed to shine through, reflecting the variations in writerly voice and national norms in spelling.

The overarching question we explore here is: how can a Batesonian perspectiveone that regards pathology as a product of the interactions of a complex ecology-guide us to re-imagine the preparation of teachers? And following from this, how might we actually prepare our preservice and in-service teachers to move past the deficit thinking model and instead create environments and relationships that will facilitate learning and the preparation of students to enter into democratic life? How can they help their students to survive the maze of conflicting educational demands that may or may not have immediate personal or cultural relevance? And how can these teachers and students together become a part of a democratic and truly inclusive society-how can we make our classrooms places that will prepare our students to take part in what Dewey (1916/1980) often referred to as "all their social relations?"

We begin by considering the vital nature of teacher-student relationships through Suzanne's work on expectancy effect: the ways in which students' perceptions and expectations of their teachers not only inform their own responses, but seem to create a self-fulfilling interaction between students and their teachers. We then juxtapose further selections from Shannon's and Serina's autoethnographic writings with work from Debbie and Kalinda on preparing preservice teachers to engage in reflective practice. This approach offers tremendous potential in facilitating understandings by teachers that will focus upon the interactions of complex systems rather than simple blaming, but also requires incorporation of some skills and concepts that are typically taught only to counseling students. Finally, we broaden our perspective and turn to the transpersonal and spiritual realm, incorporating Craig's exploration of exactly what it might mean to create classrooms as a space for facilitating human potential.

\section{Teacher-Student Interactions and the Expectancy Effect}

Child-teacher relationships have shown compelling associations with key academic outcomes from early childhood through adolescence, including motivation, engagement, performance, school behavior and social adjustment, and can buffer at-risk children against retention or referral for services (cf. Pianta, Hamre, \& Stuhlman, 2003). Childteacher rapport is thus a powerful social resource available to educators in facilitating 
positive academic outcomes for children. Yet, children's own cognitions - specifically, their expectancies - regarding their teachers might quietly undermine teachers' effective use of this resource, and consequently the positive academic outcomes it promises.

Children are both producers and consumers of their child-teacher relationships. They influence the relationship through their own characteristics (e.g., Birch \& Ladd, 1998; Dodge, Coie, \& Brakke, 1982; Brophy \& Good, 1974; Pianta, La Paro, Payne, Cox, \& Bradley, 2002), but they also anticipate, perceive, and interpret the relationship. They bring to new relationships expectations that, even in the face of evidence to the contrary, affect how they perceive peers' (Harris, Milich, Corbitt, Hoover, \& Brady, 1992; McAninch, Manolis, Milich, \& Harris, 1993) and adults' (Gurland, 2004) overtures toward them. Such expectancies and perceptions can feed back into the relationship, influencing how others actually behave toward them (Miller \& Turnbull, 1986). In the context of child-teacher relationships, this suggests that teachers are subject to children's sometimes mistaken impressions, formed on the basis of children's expectancies and subsequently confirmed by teachers' actual or projected behavior.

Suzanne and her colleagues have been studying such expectancy effects in first-time encounters between children and adults, as well as in longer-term relationships between children and their teachers. In each case, children's expectancies of adults were measured along a continuum from autonomy-supportive to controlling (Deci \& Ryan, 1985; 2002) because this dimension is salient to children, has strong motivation- and achievement-related concomitants (e.g., Ryan \& Grolnick, 1986), and has been associated with positive interpersonal outcomes (e.g., Deci \& Ryan, 1987). Autonomy-supportive styles are those that value children's perspectives, follow their initiations, and grant them developmentally-appropriate latitude in making decisions. Controlling styles assert power over children, pressure them in particular directions, and excessively constrain their choices. The researchers predicted that teachers' actual autonomy support would result in greater child-reported rapport, but that children's expectancies would also independently affect rapport. These predictions were supported in three laboratory studies and one longitudinal field study.

In the three laboratory studies, the effects of children's expectancies on relationship quality (i.e., rapport) were tested by staging laboratory-based, first-time encounters between school-age children and unfamiliar adults, akin to students meeting a new teacher on the first day of school. In the initial two studies (Gurland \& Grolnick, 2003; 2008), children in 4th through 6th grades indicated how autonomy-supportive versus controlling they expected an unfamiliar adult to be, after only glimpsing an image of her. The "teacher" then led the children through a schoolwork-like task in a video-based, "pseudo-interaction," using either an autonomy-supportive or a controlling script. Children used the Child-Adult Rapport Measure - Child Report (or CHARM-C; Gurland \& Grolnick, 2003) to indicate their perceptions of rapport with the adult. Afterwards, they repeated the procedure, but with an adult who used the other (autonomy-supportive or controlling) script. Order of conditions was counter-balanced. In both studies, children reported greater rapport with autonomy supportive adults. Moreover, in both the first $(\mathrm{F}(3,75)=6.71, \beta=0.20, \mathrm{p}<.05)$ and the second studies 
$(\mathrm{F}(1,202)=20.28, \mathrm{p}<.001, \eta 2=.09)$, children's expectancies affected rapport above and beyond the adults' actual styles. Since these were pseudo-interactions, they held the adults' contribution constant, and allowed the researchers to isolate children's contribution to the "relationship" between them. These studies constituted initial evidence that teacher-student relationship quality is neither entirely about the teachers' contribution (autonomy supportive versus controlling style) nor entirely about the children's expectancies; each of these explained unique variance.

The third laboratory study used live interactions (Gurland, 2004), and therefore had more "moving parts." Although particular adults were oriented toward particular styles of interaction, they and the children they met were responding and adjusting to one another's behavior and thereby creating their relationship in real time. Third- through sixth-grade children glimpsed one of 20 unfamiliar adult "teachers" and recorded their expectancies of her on the dimension of autonomy support to control. They then interacted with the adult pseudo-teacher over an academic task for approximately 35-50 minutes, and reported afterward on rapport, using the CHARM-C. The pseudo-teachers also provided their own ratings of rapport with the children. Hierarchical linear models, used to account for the fact that children were nested within teachers, revealed that children's expectancies $(t(56)=3.06, p<.01)$ and perceptions $(t(56)=11.63, p<.0001)$ of autonomy support each contributed uniquely to rapport. This was an important step forward, as it suggested that children's expectancies continue to exert an effect on the relationship, even with increasing familiarity with and experience of the adult. That is, experience of the actual adult did not "erase" the effect of the expectancies. What is more, since expectancies and perceptions both contributed to rapport, it was again not only the adults' styles in the interaction that determined rapport, but also the expectancies that children brought to the interaction.

These studies were still limited, of course, by constraints on ecological validity, such as the use of untrained adults posing in the role of teachers, and time-limited, single interactions. To address these issues, a field study was conducted to test whether these effects would hold up in the "living laboratory" of real classrooms (Gurland \& Evangelista, 2009). Over the summer, the researchers contacted children due to enter the 4th, 5th, or 6th grade at a large elementary school. The children had already been informed of whose class they would be joining, therefore, their summer-time expectancies of the specific teacher they had been assigned to for the coming school year could be measured. Once the school year began, teachers were asked to self-report their teaching styles on the dimension of autonomy support to control, and then children's and teachers' reports of relationship quality were measured longitudinally across the school year. Questionnaire measurements of relationship quality, from both children's and teachers' perspectives, were taken two weeks into the school year, halfway through the year, and again 30 weeks into the year. Multi-level modeling, used to account for correlation among students assigned to the same teacher, revealed that children's summertime expectancies of their teachers' autonomy support significantly predicted relationship quality, above and beyond the teachers' self-reported styles $(\mathrm{F}(1,73.44)=$ $7.55, \mathrm{p}<.01)$ with greater expected autonomy support predicting greater relationship 
quality. Further, children's expectancies predicted teachers' reports of relationship quality, again controlling for teachers' self-reported styles $(\mathrm{F}(1,71.67)=4.21, \mathrm{p}<.05)$. This latter finding suggests a true self-fulfilling prophecy (as opposed to simply a perceptual confirmation effect). In other words, it appears that children did not simply see what they expected to see, but rather, actually elicited in their teachers' behavior the very styles they had anticipated.

An additional finding from the longitudinal field study was that the teacher-toteacher variance in average relationship quality with students was negligible. In other words, there was much greater variability among the many relationships a given teacher had with his/her students than there was from one teacher to the next. This suggests that relationship quality truly is a function of the particular dyad, and not that some teachers are simply good at building rapport with students, while others are not. The study also yielded some provocative, but preliminary and not reliable, indications that children in the sample who were receiving free or reduced lunch may have expected their teachers to be more controlling. Further study will be necessary before any firm conclusions can be drawn on this front, but there exists the possibility that, due to previous experience or other factors, children in particular social categories vary systematically in how they expect to be treated by their teachers.

Converging evidence from these four studies thus suggests complex interplay between children's cognitions and their social relationships as they relate to school life. Further, they support the notion that the quality of the teacher-student relationship is coconstructed over time - not solely as a function of the teacher, nor solely as a function of the student. Schools - too often narrowly defined as a strictly cognitive realm in the current high-stakes testing environment-are in reality richly interlaced with the social, as Dewey (1916/1980) knew. Further, the social climate of school relationships - often narrowly viewed as a function of teachers' efforts - is interlaced with bi-directional contributions of children and teachers.

\section{The Legacy of the Factory Model}

The controlling model of teacher-student relationship identified by Suzanne in her experimental and classroom studies is clearly a product of the legacy described by Doll (2002) - where teaching combines the neat ordering of knowledge proposed by the thinkers of the European Enlightenment with an approach to transmission grounded in the factory efficiency models of a century ago. In these classrooms, as Aoki (1992/2005) wrote: "teachers are mere facilitators to teaching built into programmed learning packages.... a technological understanding of teaching whose logical outcome is the robotization of teaching: schools in the image of Japanese automobile factories-heaven forbid!" (p. 189). To turn away from the controlling model and instead embrace the autonomy-supportive model described by Suzanne-one that seeks to build relationship while facilitating increasing levels of independence-we must instead explore a notion of teaching as "a tactful leading that knows and follows the pedagogic good in a caring situation" (Aoki, 1992/2005, p. 191). 
Kalinda is studying one specific aspect of this in her dissertation research: the ways in which teachers understand and provide for the needs of students with chronic disruptive behaviors such as oppositional defiant disorder (ODD) - or fail to do so. Teachers' ability to implement classroom interventions for these students can have enormous influence upon the students' ability to learn. While strategies such as establishment of explicit school-wide behavioral expectations will provide adequate support for approximately $80 \%$ of students (Lewis \& Sugai, 1999), the remaining $20 \%$ will need more intensive interventions. These may include approaches such as teacher responses to help students to de-escalate rather than escalating, and the use of previously agreed-upon "time outs" where the student can remove him/herself from the classroom to calm down. Otherwise, absences, suspensions, and expulsions will lead to decrease in academic skills, increasing the chance of future academic failure (McCurdy, Manella, \& Eldridge, 2003).

Kalinda's study explores the degree to which classroom teachers understand the truly devastating consequences if their students are unable to succeed in the classroom, and whether this serves to incite empathy and an increased motivation to assist these students. Her data thus far suggests that teachers generally take one of two perspectives with these struggling students, with dramatically differing results. The first, a blaming perspective, will ultimately result in loss of the student as the teacher continues to assign the deficits entirely to the student, rather than accepting any role in problems in classroom interactions. However, the second perspective-an empathetic one-can produce a desire on the part of the teacher to assist the student, assuming the role of diagnostician and classroom action-researcher, searching for improved ways of relating to the student and helping him/her to succeed, and trying again and again until the student is reached. Even if the student never responds in terms of improved academic performance, she/he may develop some improved self-efficacy because of the teacher's belief in him/her.

\section{Reflexivity, Complexity and Complicity}

Encouragingly, as Debbie's current research reveals, there is increasing attention among educational researchers interested in reflective practice to preparing preservice teachers to consider the kinds of complex models of causation that we discuss here-as well as emerging evidence of the difficulties encountered in doing so. All too often, as studies of the development of reflective practice show, preservice teachers focus upon simplistic formulations rather than the interaction of complex dynamics in the classroom (cf. ElDib, 2007). The challenge is to guide preservice teachers away from simplistic thinking and toward "complex bridging," where they become able to identify their own ideas and beliefs and reflect upon the difficulties students encounter in the classroom in relation to those ideas, as well as the appropriate pedagogical literature (Fund, Court \& Kramarski , 2002).

Rubrics to describe and assess students' progression through levels of reflection attempt to measure not only the ability to consider student learning in relation to the 
teacher's own ideas and beliefs, but also employment of a "transformative" mode of understanding that allows complex connection to be made with the concerns and priorities of educational institutions (Ward \& McCotter, 2004). Recent work has expanded this construction still further to add explicit meta-analytic activities that incorporate a focus upon teaching as immersion in a community of practice (Watts \& Lawson, 2009). Here, we see the kinds of focus upon both complex understandings of learning, and the need to continually re-imagine the very definition of that term that a complexity approach would encompass.

In all of this, there is still an element that Debbie believes is insufficiently accounted for in existing work on reflective practice: complicity. Prior conceptions of reflective practice fall short to the degree that they position the teacher as an objective bystander, carrying out analysis and working from a position that is able to stand outside the system. Rather, Debbie believes that we must turn toward an understanding the teacher as an active agent within the system-much as we see in Mary Catherine Bateson's iterative examinations of the dynamic of the family and counselor (N. Bateson, 2009). As Suzanne's work suggests also, this layer of complexity theory moves us to ask teachers to "consider how they are implicated in the phenomena that they study," and to keep constantly in mind that "it is not just about the object, not just about the subject, and not just about social agreement. It is about holding all of these in dynamic, co-specifying, conversational relationships... in an always-evolving, ever-elaborative structural dance" (Davis \& Sumara, 2006, pp.15-16).

Aoki's (1987/2005) antidote to the alienation of the mechanized and transmissionbased classroom strikes a similar note: teaching must be understood "not only as a mode of doing but also as a mode of being-with-others" (p. 359), a posture that also seems congruent with a clear recognition of complicity in the classroom system. As Davis \& Sumara (2006) pointed out, as much as constructivist theory to date has worked to dismantle the mechanistic notions of transmission as the basis of learning, it still fundamentally presumes that the individual is the locus of the educational process. But what happens to our conception of teaching and learning if we move to understand our classrooms as complex social collectives? How does embracing Aoki's notion of teaching as a mode of "being-with-others" fundamentally change our views of teaching and teacher preparation?

\section{Relationship, Culture and Care in the Classroom}

If we accept that the teacher is complicit in the classroom system, it becomes even clearer that teachers need preparation in interpersonal dynamics - an area that, as Kalinda notes, while routinely part of counselor training, is seldom if ever incorporated into teacher preparation. For example, during the first semester of graduate education, counseling students typically complete a course in which they increase self-awareness as they learn and practice purposeful communication techniques (Ivey, Ivey, \& Zalaquett, 2010). These techniques are derived from Carl Rogers' (1961) conceptualization of a helper as a person who is congruent, accepting, and empathetic. Congruency occurs 
when the helper is genuine and transparent. This, in turn, provides the person being helped with a sense that the helper is trustworthy, dependable, and consistent. Acceptance involves unconditional positive regard toward the person being helped. This assists the person being helped to experience self-acceptance which leads to the pursuit of a deeper and more accurate self-exploration coupled with a change in negative selfbeliefs (Thorne, 1992). Empathy requires that the helper sensitively and accurately perceive the world of the one being helped as this individual sees it (Rogers, 1961). In order to actively utilize congruence, acceptance, and empathy, these principles are reinforced throughout graduate training.

As counselors-in-training interact with clients, they are encouraged to reflect upon the roles of transference and countertransference. Transference was first introduced to psychology by Sigmund Freud (1989; 1995), who defined it as the process that occurs when a client's unconscious concepts of interpersonal relationships, which form early in development, are projected into the relationship with the therapist. These projections can occur in the form of interpersonal expectations, resistance, suspicions, intense emotions, and/or beliefs (Mitchell \& Black, 1995). On the other hand, countertransference is defined as the counselor's interpersonal reactions to the client (Mitchell \& Black, 1995). The source of countertransference may be either the therapist's or the client's previously formed interpersonal relational concepts (Miller \& Stiver, 1997) Specifically, when counseling students are in practicum learning to engage in the therapeutic relationship, it is not uncommon for a supervisor to ask questions such as: "What are you thinking or feeling toward the client? Are you behaving differently toward this client than others? What personal factors, on the part of the client and on the part of you, the therapist, may be contributing to your reactions to this client?" By utilizing information from the process of transference and countertransference, the relational images of the client, which contribute to the health of inter- and intrapersonal relationships, can be understood and guided toward healthiness (Miller \& Stiver, 1997).

It is a short conceptual leap to see how these issues relate also to the role of the teacher. Students enter classes with expectations and relational models of persons in authority, which are mediated by their own past experiences as well as specific characteristics of the teacher such as gender, ethnicity, and personality (Bowlby, 1982); however, students are not alone in their unconscious relational conceptions. The psychological processes of transference and countertransference are present on both sides of interpersonal classrooms encounters, but when teachers lack awareness of their own relational models and the preparation to examine those in relation to their classroom relationships, the potential exists for unhealthy and un-productive classroom relational interactions.

These relational aspects are complicated still further by cultural differences. One recent study found that while $76 \%$ of first-year teachers surveyed reported having taken coursework that dealt with diversity, only 39\% found this work helpful and relevant once they were in their own classrooms. (National Comprehensive Center for Teacher Quality \& Public Agenda, 2008). Negotiating culture in the classroom was something 
that Serina and Shannon-like too many new teachers-had to discover on their own. Most of Serina's students, for example, were African American:

It was not long before I began questioning this seeming disparity. After all, my personal experiences of going to school in majority minority schools taught me that these students were my peers, and I never noticed any striking disparities that told me skin color created some intractable difference or inferiority. Being on the "flip side" of the equation, I began to understand the retrospectively racist and prejudicial remarks of my colleagues. Even though I knew these thoughts and comments to be horribly wrong and detrimental to the learning process of our students, I did understand where they were coming from.

The frequent relocations of her military family as a child gave Shannon the opportunity to interact with many different students from many different backgrounds. Her relations with students of color are a reflection of those experienced by many white women (Sleeter, 1993):

Many of the small towns I lived in had strong Native American populations. These families were assumed to be poor, with bad parents who were struggling with drugs and alcohol. "They" were oppressed by a government system that took choices away. I was conditioned to feel sorry for those kids. Their poor behaviour and/or lack of academic achievement were to be excused because they were negotiating lives that were much harder than mine. By the time I reached high school, in a large suburban district, I did have friends of colour, mostly from Indian and Asian families, who were in my AP classes. There were black kids in my high school, but I had no classes with them, and didn't interact with them socially. Again, as with Native Americans, there was an underlying assumption that they were somehow different. I engaged in a cultural idea of "colour-blind racism" even failing to identify my best friend as a person of colour. Possibly, because I had no need to feel sorry for her, I failed to see her ethnicity. As a teenager, the race of my friends meant nothing to me, except as interesting food and cultural experiences. The race of people who weren't my friends meant only that they were outside of my consciousness.

In the field of counseling training, by contrast, multicultural competencies and standards were proposed by Sue, Arredondo, and McDavis (1992) and have since been accepted by the counseling community. The first characteristic of a culturally competent counselor is one who is actively involved in the process of self-awareness regarding personal cultural beliefs, assumptions, and biases. The second characteristic, closely linked to Rogers' (1961) concept of empathy, requires the counselor to be actively involved in the process of understanding "the worldview of his or her culturally different client without negative judgments" (Sue, Arredondo, \& McDavis, 1992, p. 471). Lastly, culturally competent counselors are involved in the on-going process of learning and utilizing culturally appropriate interventions with clients.

If we are to reject the kinds of "color blindness" that deny culture and identity and reify the normative constructions of whiteness (cf: Howard, 1998), and also to engage and embrace students of all backgrounds and levels of ability, what kinds of possibilities exist for pedagogical relationship? Gere, Hoshmand and Reinkraut (2002) have characterized the essential quality of engagement for teachers in terms of empathy--"the capacity for full engagement with the personal reality of others,--and aesthetic regard-"a deep appreciation for the uniqueness and value of each individual" (p. 155). They 
invoke the thought of Martin Buber to theorize the creation of a sacred space in the classroom where both empathy and aesthetic regard can flourish.

Buber's (1923/1937) description of the reduction of another to an inhuman It, rather than a personal and intimate Thou provides, we believe, a powerful insight into the dynamic that prevails when deficit thinking and blame infuse classroom relationships: It "has no part in the experience. It permits itself to be experienced, but it has no concern in the matter. For it does nothing to the experience, and experience does nothing to $I t^{\prime \prime}$ (p. 5). Thus, for example, when the teacher's judgment of a student derives entirely from the student's academic achievement, the teacher has reduced the student to "a specific point in space and time... a loose bundle of named qualities... [where] he ceases to be Thou and instead is reduced to an $I t^{\prime \prime}$ (pp. 8-9).

Drawing these ideas together, we gain a commitment to acknowledging the complicity of self, and to rejecting metanarrative constructions and the tendency to colonize others who are different from ourselves. Rather, we must prepare our preservice teachers to accept and come into relationship with incommensurability, variety, and change. This, as Doll (1999) sees clearly, is a deeply radical move: "Wow! Oh Wow! Developing an on-going "self-conscious sensitivity of the need always to do justice to 'the Other's' singularity!' What does this do to our concepts of ethics and education?" (p. 90). Craig's recent work explores this question, taking up the question of what it might mean to view teacher preparation and teacher-student relationship from a very different perspective.

\section{Towards a phenomenology of the coauthoring of selves}

During the last 30 or 40 years, practitioners in the field of philosophy of education have generally moved away from treating teacher education or classroom dynamics as their primary foci, swept up instead into the powerful philosophical movement known as postmodernism, and its primary proponents such as Michel Foucault, Jean-François Lyotard, and Jacques Derrida. These thinkers have emphasized the importance of narratives, language, meaning, power, and the social construction of truth, thereby undermining modernism's faith in the possibility of objective knowledge as well as the alleged superiority of science over other approaches to understanding reality. Central to this postmodernist project was its emphasis on human diversity, and on the incapacity of modernism and other so-called meta-narratives to capture the full breadth of human experience among different races, ethnicities, cultures, and gender roles. Postmodern philosophy of education distanced itself from the daily practice of teaching in favor of a trenchant critique of modern culture, replacing belief in any overarching social ideal with a stance of irony and disbelief. In some ways, postmodernism even motivated a turn away from faith in democracy, since in the postmodern view was that there is no escape from unequal power relations, no matter how many procedural safeguards are in place.

However, the story does not end there. Despite its sometimes distracting agenda, postmodernism opened the philosophy of education community to the importance of 
human diversity and the inevitability of pluralism, and thus paved the way for a new revolution in thinking about education. While modernist education had sought to overcome human diversity in the effort to create a common culture based on rational virtue, postmodernism raised the possibility that this approach was hegemonic, and therefore should be resisted. However, this call for resistance left many teachereducators with the following poignant question: if all meta-narratives must be deconstructed in the face of previously marginalized perspectives, then what roleother than spreading ironic detachment-might schools play that could reconnect citizens to the common good?

Fortunately, one branch of postmodernism-phenomenology-has developed an answer to this question. Phenomenology seeks to overcome a purely subjective or personal understanding of consciousness in favor of systematic reflection on lived experience. Like other forms of postmodernism, phenomenology includes a radical critique of the modern ideal of objectivity. However, rather than merely deny the possibility of objectivity, phenomenology replaces it with a new idea: "intersubjectivity." While each person is inherently subjective in the sense that they have a personal perspective that cannot be escaped, intersubjectivity acknowledges that each person can come to a mutual understanding not only of the subjectivity of others, but that one's own self is an "Other" in other people's experience. Each person, that is, recognizes that he or she is both a subject of one's own perspective and an Other in every other person's perspective. We are all subjective and therefore subject to bias and insensitivity towards others, but since we all are subjective, we can establish a basis upon which meanings may be communicated and shared even though each other person's perspective is fundamentally irreconcilable with our own.

Emmanuel Levinas (2006), a student of both Husserl and Heidegger, took the idea of intersubjectivity further: while a given person, or subject, may establish effective communication with an Other, the Other is never fully knowable and can never be fully assimilated into one's self. The Other's Otherness, or "alterity," is absolute. He or she expresses aspects of human possibility that I or we have never experienced. This means that any encounter with an Other person is potentially life-changing. From this perspective, the existence of the Other person demands recognition, while at the same time it opens one's own perspective to a potentially violent critique, since the alterity of the Other implicitly denies that one's own perspective is completely true or is all that it can or should be. What's more, each encounter with an Other demands a response. While it is possible simply to deny the person's Otherness or to objectify the person by assigning him or her to a stereotype or other category, an ethical person responds to the encounter by both noticing the subjectivity of the Other (and thus affirming intersubjectivity) and at the same time acknowledging that the Other is of ultimate moral worth, both in the sense that he or she is unique and therefore irreplaceable and also in the sense that she or he offers a unique glimpse of the possibilities for the future growth of one's self.

This recognition of the value of the Other echoes the notion of George Herbert Mead (1934), , who believed that one becomes conscious of one's self only by taking on 
the perspective of the other towards oneself, using the other as a sort of mirror. We become increasingly aware of ourselves only by seeing ourselves from perspectives that are outside of ourselves, that is, through the eyes of the other. Thus-and this is a critical point--other persons are absolutely essential for development of one's self. What's more, because we cannot possibly know the consequences of becoming other than we are, or know how we might see ourselves once we are changed, it is impossible to adequately prejudge any pathway that opens up for our own growth (Deleuze 1997). We cannot, therefore, ever judge a person as lesser than we are merely because their perspective is different than ours. Every perspective is unique, and uniquely valuable, in a way that simply cannot be compared by any objective measure.

In coming to this realization, postmodern philosophers have done more than merely deconstruct the modernist meta-narrative about the purpose of public schools; they have also provided a basis for conceiving of that purpose in a new way. By bringing diverse young members of the community together into a common space, public schools create an arena for each of them to develop in an environment of otherness that the students would be quite unlikely to have access to at home. Thus, in a democracy, public schools can go beyond preparing students to deal with diversity; their very diversity creates the optimal conditions for developing each student's unique potential.

\section{How Would a Focus on Unique Potential Transform Schools?}

John Dewey (1916/1980) believed that democracy is more than a form of government; it is "primarily a mode of associated living, of conjoint communicated experience" (p. 93), characterized by both freedom of association among groups in the society and with other societies and by a commitment to developing shared interests in the process of decision-making. Participation in shared decision-making requires continual communication among the members of the society so that each person maintains a strong sense of the perspectives of other members as they engage in dialog about mutually beneficial forms of social action. In the process, citizens often refine their private desires as well, while building the capacity for imagination, sensitivity, and selfreflection and subjecting their personal interests to implicit critique by the interests of others. For Dewey (1939/1989), a democratic society seeks to utilize "plural, partial, and experimental methods in securing and maintaining an ever-increasing release of the powers of human nature, in service of a freedom which is cooperative and a cooperation which is voluntary" (pp. 187). Participation in this experimental approach to inquiry was, for Dewey, not only central to democratic life but also an effective form of education for democracy, leading him to an abiding commitment to making schools into a form of social life rather than mere preparation for such a life (Johnston, 2006).

The multiple perspectives that one encounters in a democracy causes each person to continually reconstruct their own experiences - to refine their ideas and habits - thus releasing more of their individual potentialities. This release, Dewey (1920/1982) writes, is the very function of social institutions: 
All social institutions have a meaning, a purpose. That purpose is to set free and to develop the capacity of human individuals without respect to race, sex, class, or economic status. And this is all one with saying that the test of their value is the extent to which they educate every individual into the full stature of his possibility. Democracy has many meanings, but if it has a moral meaning, it is found in resolving that the supreme test of all political institutions and industrial arrangements shall be the contribution they make to the all-around growth of every member of society (p. 186).

The connection of democracy and education is clear: a society is democratic to the extent that each member of the society is able to develop themselves fully, "into the full stature of his [sic] possibility." It is this connection that is the focus here.

A common mythic conception of individuality found in many traditions is that each person has a "higher self," genius, soul, or daimon that represents the fullness of one's potential powers. This daimon, often deemed to be given by God and embodying divine purposes, accompanies each person through life and connects her in some special and personal way to her destiny. This view holds that each person has a unique set of qualities, interests, talents, or potentials which demand expression if the person is to find fulfillment in life. Plato (1974) wrote of the daimon at the end of his most wellknown work, the Republic, and in Aristotle's Nicomachean Ethics (1962) one finds this idea in the concept of eudaimonia-commonly translated as "happiness" but having a richer etymology as "living in harmony with one's higher self" - which represents the highest reward for living virtuously.

Perhaps the best scholarly source for an understanding of the idea of the daimon as it appears in ancient Greek thought is David Norton (1976). Norton suggests that each person's "unique potential excellence" can serve as a guide to making choices with moral consequences, and that the only way a person "can manifest worth in the world only by living in accordance with his destiny" (p. 16). In The Soul's Code: In Search of Character and Calling, James Hillman (1996) explores the cultural implications of this idea, presenting it as a useful frame for understanding human development. Hillman labels this the "acorn theory" to refer to the notion that the acorn contains or presages the potential mature oak, just as the daimon contains or presages the potential fulfilled human being. Hillman writes:

Each person enters the world called.... The soul of each of us is given a unique daimon before we are born, and it has selected an image or pattern that we live on earth. The soul-companion, the daimon, guides us here; in the process of arrival, however, we forget all that took place and believe we come empty into this world. The daimon remembers what is in your image and belongs to your pattern, and therefore your daimon is the carrier of your destiny. (p. 8)

For Hillman, the daimon has the individual's "interest at heart" (p. 12), preserves him or her from harm, and often provides a "call" to a particular profession or activity that "rings loud and persistent and is as demanding as any scolding voice from the surroundings" (p. 13). This "call" is seen most clearly in the pivotal events in the lives of certain famous people, for example when sixteen-year old Ella Fitzgerald decided to sing rather than dance (as had been her plan) at Amateur Night at the Harlem Opera 
House, or when the great violinist Yehudi Menuhin refused a toy violin given him by a family friend, insisting upon having the real thing. Hillman's book is based upon an examination of the events of extraordinary lives as a way, Hillman insists, to uncover the extraordinary quality of many ordinary events, "to inspire ordinary lives by displaying their own potentialities" (p. 32). This idea of a "call" can also be seen in the motivation of many people to become a teacher (Hansen 1995).

On Hillman's view, contemporary psychology, like other modern sciences, has ignored traditional ideas such as that of the daimon (and the "providence" it brings into ordinary lives) and has therefore become blinded to the deeper reasons why some people achieve greatness while others are trapped in meaninglessness or obscurity. By focusing only upon what can be seen or measured, Hillman claims, psychology fails to understand the crucial importance of factors such as destiny, calling, and imaginative vision in the development of fulfilled persons. This failing is especially evident in educational psychology's treatment of exceptional children and their various clinically defined "symptoms" of depression, alienation, hyperactivity, problems of social adjustment, or drug abuse. Rather than seeing such symptoms as clues to the inner genius of these children, they are often "treated" in the attempt to bring their behavior more into line with what is considered "normal." Hillman also criticizes the tendency of educational institutions to judge students according to norm-referenced tests, the desire (whether expressed or implied) of many educators and schools for "order" and compliance with certain norms, the recent fixation among educational leaders for standards of evaluation and instruction, and the practice of many parents-out of anxiety more than anything else-to compare their children to other children to ascertain whether they are doing the right things. Most of these tendencies and practices are based upon a very different set of assumptions about human nature.

Suppose that Hillman's thesis is correct, that each of us is gifted with a unique potential (or daimon) which defines a destiny, and that successful maturation depends upon finding a way to live life in accordance with this daimon and the destiny it carries. Suppose further that those students who emerge from our educational institutions with a deep understanding of who they are, where they are going in their lives, and what (at least partially) they need to do to get there are more likely to succeed in life than those who have merely learned the academic lessons offered in school or who have shown, by compliance with external rules and expectations, a certain docility of character that leads to success in school but has little to do with the truth of the inner daimon. Suppose still further that students who rebel from parental and institutional expectations-such as those who use illegal drugs or engage in other criminal behavior, or who choose to skip school rather than put up with its common mindlessness - are in fact expressing the lack of fit between their personal destinies and institutional norms. If all these suppositions were true, shouldn't we reconceive the purposes and structures of schools? Instead of aiming to teach certain facts and skills, shouldn't we concentrate on helping each student to find a sense of larger purpose and meaning? Instead of punishing or treating non-compliance, shouldn't we seek to understand the underlying motivations so that we can better provide our youngsters with the guidance they may need to find a fit between 
their unique potentials and the actual world we live in? And perhaps most importantly for our purposes here, shouldn't it be a primary purpose of teacher education to prepare teachers for the task of helping students to get in touch with their destinies?

\section{Conclusions and Implications}

The construction of the original symposium and this paper follow Bateson's (1941/2000) advocacy for a variety of approaches, given that "advances in scientific thought come from a combination of loose and strict thinking, and this combination is the most precious tool of science" (p. 86). While historically this has tended to happen by chance, Bateson advised that researchers consciously alternate between them: that they "accept and enjoy this dual nature of scientific thought and be willing to value the way in which the two processes work together to give us advances in understanding of the world" (p. 86). In our case, while each of our works reflects a distinct approach, collectively we brought together varying qualitative and quantitative modes - and individuals expert in each-to consider a complex web of theorization and empirical detail.

As we have come to see through this process, metaphorically "walking around" an area of inquiry and viewing it from multiple perspectives can bring into focus a dizzying array of insights and ideas. The opportunity to move among these layers of research and discourse, including the speculative-to "level-jump" - is a particular reason to embrace complexity thinking, since "complexity theories are also attentive to the possibility of emergent, transcendent forms...complexity is incompressible and ever-expanding" (Davis \& Sumara, 2006, p. 34). At the same time, we freely admit, a complexity approach can confound all attempts to neatly encompass and describe the phenomenon under study, and that can be unsettling. As Suzanne observed during our panel presentation, bringing together research paradigms that are commonly perceived as being in competition with one another is at once anxiety-provoking and invigorating. It may become a source of trepidation as we fear our accustomed research tradition might become the object of ridicule or condemnation; yet it offers excitement and affirmation as we affirm and re-engage our own perspectives while becoming enriched by encounters with one another. To engage this process at all requires an ethic of precarity: "a condition of vulnerability relative to contingency and the inability to predict" (Ettlinger, 2007, p. 319).

Based upon our experiences together, though, we would argue strongly for the value of these kinds of uncertainty-inducing experiences - indeed for embracing them. Following upon Bateson's (1941/2000) argument for intentionally alternating among the "loose" and "strict" approaches to research, we believe that the intentional juxtaposition of our various modes of inquiry - the autoethnographic, quantitative, philosophic and qualitatively empirical - further enriches the potential for complexity-based research to become "a powerful alternative to the linear, reductionist approaches to inquiry that have dominated the sciences for half a millennium - and educational research for more than a century" (Davis \& Sumara, 2006, p. xi). 
Among the multiplicities that we encompass here, we found areas of connection and consensus-strands that appeared again and again across our writings and discussions. To embrace each student as a unique individual, as we all would advocate - and to thoughtfully do this in a manner that fosters democracy and facilitates robust learning for students of all cultures and backgrounds-requires very different teaching and thus a very different mode of teacher preparation than that which is common today. Teachers, clearly, must be prepared to engage in a much "more difficult kind of planning"; able to "survey the capacities and needs of the particular set of individuals...[and] at the same time arrange the conditions which provide the subjectmatter or content for experiences that satisfy these needs and develop these capacities" (Dewey 1938/1988, p. 36). They must be equipped to draw from a range of skills and knowledge that exceeds those typically included in teacher education programs; at a minimum, training in interpersonal skills is desperately needed.

Along similar lines, as our converging understandings of the classroom as an ecology that is based upon continual co-creation and mutuality suggest, students will only learn how to develop their own unique potentials if they see the adults in their lives doing likewise. Teachers, therefore, have a fundamental professional obligation to openly acknowledge their complicity in the systems they occupy, and to engage in a process of continual, public, personal self-improvement. By revealing themselves to be continually struggling to live according to their own unique potentials, and by demonstrating a properly open attitude toward the diverse potentials of their students and others, teachers can have a much more profound effect on their students than if they confine themselves to academic subject-matter. Teachers must serve as examples in at least two respects: they must show "exceptional candor and openness" so that students can see the difficulties and the rewards of engaging in self-actualization, and they also must demonstrate understanding of the role of other people in development of the self, that is, "the recognition that outside my personal destiny lies a multitude of truths which, though not my own, are other people's. On this basis [they are] required to foster and encourage destinies different from [their] own" (Norton, 1973, p. 114-115).

Preservice teachers, to be prepared for this, would be expected to go through a welldeveloped curriculum in imagination and the formation of ideals for themselves before they are deemed to be ready to support the process with their students, the students' parents, and the teacher's colleagues, throughout their career. This approach, with its focus upon the spiritual and transpersonal aspects of self, other, and of teaching, may seem to edge uncomfortably close to the realm of religion. Here, we follow Dewey (1934/1986) - who began his scholarly career as an outspoken critic of religion-in suggesting that we can think about ideals that have effect upon the transpersonal level without having to become grounded in any specific construction of religion. As he observed, "Any activity pursued in behalf of an ideal and against obstacles and in spite of the threats of personal loss because of conviction of its general and enduring value is religious in quality" (p. 27).

Some of the ideas that we share here certainly enter into areas that Dewey might categorize as matters of faith: our advocacy for a focus upon pedagogical relationship 
rather than the transmission of content; the embrace of diversity and multicultural perspectives; the care and concern for students' development of autonomy-all engage multiple levels of personal and societal values and ethics. The issues involved include judgments as to the nature of democratic citizenship and effective preparation for that goal, as well as the nature of the relationship between self and other.

As we saw through our own experiences in creating this work, the juxtaposition and integration of our individual writings, and especially our conversations around these processes, has become a mode of inquiry in itself. We have to a large degree abandoned the conventional qualitative mode of triangulation, which combines different methods to validate results by demonstrating that each method yields results that agree-an approach that assumes that there is "a 'fixed point' or an 'object' that can be triangulated." We instead embrace "crystallization," which "combines symmetry and substance with an infinite variety of shapes, substances, transmutations, multidimensionalities, and angles of approach." Critically, this perspective reminds us that: "what we see depends on our angle of repose" (Richardson \& Adams St. Pierre, 2005, p. 963). In this sense, as we believe our joint work illustrates, "understanding is not the point...cutting from these pieces, transcending what they...(re)present, is to be complicit in enlarging the space of the possible" (Osberg, 2010, p. vii). We share our work with our readers in the hope that they, too, will be able to cut from this - to take what is useful to them and to take part in enlarging the space of our discussions and deliberations.

\section{References}

Alexander, T.M. (1995). Educating the human heart: Pluralism, traditions and the humanities. In J. Garrison (Ed.). The new scholarship on Dewey (pp. 75-84). Boston: Kluwer Academic Publishers.

Aoki, T.T. (2005) Inspiriting the Curriculum (1987). In W.F. Pinar \& R.L. Irwin (Eds.) Curriculum in a new key: The collected works of Ted T. Aoki (pp. 357-365). Mahwah, NJ: Lawrence Erlbaum Associates.

Aoki, T.T. (2005). Layered voices of teaching: The uncannily correct and the elusively true (1992). In W.F. Pinar \& R.L. Irwin (Eds.) Curriculum in a new key: The collected works of Ted T. Aoki (pp. 187197). Mahwah, NJ: Lawrence Erlbaum Associates.

Aristotle, with Martin Ostwald. (1962). Nicomachean ethics. Indianapolis: Bobbs-Merrill.

Bateson, G. (2000). Experiments in thinking about observed ethnological material. In Steps to an ecology of mind (pp. 73-87). Chicago: The University of Chicago Press. (1941).

Bateson, N. (2009). An ecology of mind. [Film - Unedited version]. United States: Nora Bateson. (http://www.anecologyofmind.com/Page 2.html)

Biesta, G.J.J. (2006). Beyond learning: Democratic education for a human future. Boulder, CO: Paradigm Publishers.

Birch, S. H., \& Ladd, G. W. (1998). Children's interpersonal behaviors and the teacher-child relationship. Developmental Psychology, 34, 934-946.

Bochner, A.P. (1997). It's about time: Narrative and the divided self. Qualitative Inquiry, 3(4), 418-438.

Bowlby, J. (1982). Attachment and loss (2 $2^{\text {nd }}$ ed.). New York: Basic Books.

Brophy, J., \& Good, J. L. (1974). Teacher-student relationships. New York: Holt, Rinehart \& Winston. Buber, M. (1937). I and Thou. (R.G. Smith, Trans.). New York: Charles Scribner's Sons. (1923).

Davis, B \& Sumara, D. (2006). Complexity and education: Inquiries into learning, teaching, and research. New York: Lawrence Erlbaum Associates. 
Deci, E. L., \& Ryan, R. M. (1985). Intrinsic motivation and self-determination in human behavior. New York: Plenum Publishing Co.

Deci, E. L. \& Ryan, R. M. (1987). The support of autonomy and the control of behavior. Journal of Personality and Social Psychology, 53, 1024-1037.

Deci, E. L., \& Ryan, R. M. (Eds.), (2002). Handbook of self-determination research. Rochester, NY: University of Rochester Press.

Deleuze, G. (1997). Essays critical and clinical. Minneapolis: University of Minnesota Press.

Dewey, J. (1986). A common faith. In J.A. Boydston (Ed.) John Dewey: The later works, 1925-1953, (Vol. 9), (pp. 1-58). Carbondale: Southern Illinois University Press. (1934).

Dewey, J. (1980) Democracy and education. In J.A. Boydston (Ed.) John Dewey: The middle works, 18991924, (Vol. 9), (pp. 1-370). Carbondale: Southern Illinois University Press. (1916).

Dewey, J. (1988). Experience and education. In J.A. Boydston (Ed.) John Dewey: The later works, 1925-1953, (Vol. 13), (pp. 1-62) Carbondale: Southern Illinois Univ. Press. (1938).

Dewey, J. (1989). Freedom and culture. In J.A. Boydston (Ed.) John Dewey: The later works, 1925-1953, (Vol. 13), (pp. 63-188) Carbondale: Southern Illinois Univ. Press. (1939).

Dewey, J. (1982) Reconstruction in philosophy. In J.A. Boydston (Ed.) John Dewey: The middle works, 18991924, (Vol. 12), (pp. 77-202) Carbondale: Southern Illinois University Press. (1920).

Dodge, K. A., Coie, J. D., \& Brakke, N. P. (1982). Behavior patterns of socially rejected and neglected preadolescents: The roles of social approach and aggression. Journal of Abnormal Child Psychology, 10, 389-410.

Doll, W.E., Jr. (2002). Beyond methods? Teaching as an aesthetic and spirit-ful quest. In E. Mirochnik \& D.C. Sherman (Eds.) Passion and pedagogy: Relation, creation, and transformation in teaching (pp. 127151). New York: Peter Lang.

Doll, W.E., Jr. (1999). Conversing with the Other. Journal of Curriculum Theorizing 15(3), 83-90.

El-Dib, M.A.B. (2007). Levels of reflection in action research. An overview and an assessment tool. Teaching and Teacher Education 23(1), 24-35.

Ettlinger, N. (2007). Precarity unbound. Alternatives 32, 319-340.

Freud, S. (1989). Fragment of an analysis of a case of hysteria ("Dora"). In P. G. Gay, The Freud reader, p. 172-237. New York: W. W. Norton and Company.

Freud, S. (1995). The psychology of the dream process. In A. A. Brill, The basic writings of

Sigmund Freud, p. 436-517. New York: Modern Library.

Fund, Z., Court. D. \& Kramarski, B. (2002). Construction and application of an evaluative tool to assess reflection in teacher-training courses. Assessment \& Evaluation in Higher Education 27(6), 485-499.

Gere, S.H., Hoshmand, L.T. \& Reinkraut, R. (2002). Constructing the sacred: Empathic engagement, aesthetic regard, and discernment in clinical teaching. In E. Mirochnik \& D.C. Sherman (Eds.) Passion and pedagogy: Relation, creation, and transformation in teaching (pp. 153-176). New York: Peter Lang.

Gurland, S. T. (2004). Adult styles of interaction and children's expectancies: Implications for clinical rapport. Doctoral dissertation, Clark University.

Gurland, S. T. \& Evangelista, J. (2009, April). Teacher-student relationship quality over time: A socialcognitive perspective. Symposium presented at the biennial meeting of the Society for Research in Child Development, Denver, CO.

Gurland, S. T. \& Grolnick, W. S. (2003). Children's expectancies and perceptions of adults: Effects on rapport. Child Development, 74, 1212-1224.

Gurland, S. T. \& Grolnick, W. S. (2008). Building rapport with children: Effects of adults' expected, actual, and perceived behavior. Journal of Social \& Clinical Psychology, 27(3), 226-253.

Hansen, D. T. (1995). The call to teach. New York: Teachers College Press.

Harris, M. J., Milich, R., Corbitt, E. M., Hoover, D. W., \& Brady, M. (1992). Self-fulfilling effects of stigmatizing information on children's social interactions. Journal of Personality and Social Psychology, 63, 41-50. 
Hillman, J. (1996). The soul's code: In search of character and calling. New York: Random House.

Howard, G.R. (1999). We can't teach what we don't know: White teachers, multiracial schools. New York: Teachers College Press.

Ivey, A. E., Ivey, M. B., \& Zalaquett, C. P. (2010). Intentional interviewing and counseling: Facilitating client development in a multicultural society. Belmont, CA: Brooks/Cole.

Johnston, J.S. (2006). Inquiry and education: John Dewey and the quest for democracy. Albany: State University of New York Press.

Lévinas, E. (2006). Humanism of the other. Urbana: University of Illinois Press.

Lewis, T. J., \& Sugai, G. (1999). Effective behavior support: A systems approach to proactive schoolwide management. Focus on Exceptional Children, 31(6), 1-24

Macbeth, D. (2001). On "reflexivity" in qualitative research: Two readings, and a third. Qualitative Inquiry, 7(35), 35-68.

McAninch, C. B., Manolis, M. B., Milich, R., \& Harris, M. J. (1993). Impression formation in children: Influence of gender and expectancy. Child Development, 64, 1492-1506.

McCurdy, B. L. Manella, M. C., \& Eldridge, N. (2003). Positive behavior support in urban schools: Can we prevent the escalation of antisocial behavior? Journal of Positive Behavior Interventions, 5, 158170.

Mead, G.H. (1934). Mind, self, and society. C.W. Morris, (Ed.). Chicago: University of Chicago Press

Miller, D. T., \& Turnbull, W. (1986). Expectancies and interpersonal processes. Annual Review of Psychology, 37, 233-256.

Miller. I. P. \& Stiver, J. B. (1997). The healing connection. Boston: Beacon Press.

Mitchell, S. A., and Black, M. J. (1995). Freud and beyond. NewYork: Basic Books.

National Comprehensive Center for Teacher Quality \& Public Agenda (2008). Lessons learned: New teachers talk about their jobs, challenges, and long-range plans. Downloaded at http://www.publicagenda.org/reports/lessons-learned-new-teachers-talk-about-their-jobschallenges-and-long-range-plans-issue-no-1

Norton, D.L. (1995). Education for self-knowledge and worthy living. In J. Howie \& G. Schedler (Eds.) Ethical Issues in Contemporary Society (pp. 155-176). Carbondale: Southern Illinois Univ. Press.

Osberg, D. (2010). Knowledge is not made for understanding: It is made for cutting. Complicity: An International Journal of Complexity and Education 7(2), iii-viii.

Pianta, R. C., Hamre, B., \& Stuhlman, M. (2003). Relationships between teachers and children. In W. Reynolds and G. Miller (Eds.), Comprehensive handbook of psychology (Vol. 7) Educational psychology, pp.199-234. Hoboken, NJ: Wiley.

Pianta, R., La Paro, K., Payne, C., Cox, M., \& Bradley, R. (2002). Observed quality of the kindergarten classroom environment: Description and relations with teacher, family, and school characteristics and child outcomes. Elementary School Journal, 102, 225-238.

Plato, with G. M. A. Grube. (1974). Plato's Republic. Indianapolis: Hackett.

Richardson, L. \& Adams St. Pierre, E. (2005). Writing: A method of inquiry. In N.K. Denzin \& Y.S. Lincoln (Eds.) The Sage handbook of qualitative research (3 ${ }^{\text {rd }}$ ed.). Thousand Oaks, CA: Sage Publications.

Rogers, C. R. (1961). On becoming a person: A therapist's view of psychotherapy. Boston: Houghton Mifflin Company.

Ryan, R. M. \& Grolnick, W. S. (1986). Origins and pawns in the classroom: Self-report and projective assessments of individual differences in children's perceptions. Journal of Personality and Social Psychology, 50, 550-558.

Sleeter, C.E. (2005). Un-Standardizing curriculum: Multicultural teaching in the standards-based classroom. New York: Teachers College Press.

Sue, D. W., Arredondo, P., \& McDavis, R. J. (1992). Multicultural counseling competencies and standards: A call to the profession. Journal of Counseling and Development, 70, 477-486.

Thorne, B. (1992). Carl Rogers. London: Sage Publications. 
Ward, J.R. \& McCotter, S.S. (2004) Reflection as a visible outcome for preservice teachers. Teaching and Teacher Education 20(3) 243-257.

Watts, M. \& Lawson, M. (2009). Using a meta-analysis activity to make critical reflection explicit in teacher education. Teaching and Teacher Education 25(5), 609-616.

\section{Acknowledgements}

This paper is drawn from a symposium presentation for the Chaos \& Complexity SIG at the 2010 Annual Meeting and Conference of the American Educational Research Association (AERA). We wish to thank our respondents at that session-Barney Ricca and Sherrie Reynolds - as well as the attendees for their comments and insights, which helped to guide the creation of this paper.

\section{About the Author/s}

Deborah Seltzer-Kelly is an assistant professor in the Faculty of Curriculum Studies in the Department of Curriculum and Instruction at Southern Illinois University, Carbondale. Her career history has included over a decade as a designer and manager for the commercial construction industry, as well as several years as a high school history teacher, middle school speech and theater teacher, and competitive collegiate debate coach. She is particularly interested in constructions of method in teaching and research, and works at the intersection of philosophy of science and philosophy of education to explore this topic. Her previous work has appeared in educational journals including Educational Theory and Studies in Philosophy and Education. email: dseltzer@siu.edu

Serina Cinnamon is a doctoral student at Southern Illinois University-Carbondale. Her research interests include teaching for democracy and democratic citizenship, the history of teaching democratic values, multicultural representations in curriculum as a way of promoting democracy, Deweyian notions of democracy and pragmatism and exploring differing notions of democracy across nations.

Craig A. Cunningham, Ph.D. is associate professor in the department of Integrated Studies of Teaching, Technology, and Inquiry at National-Louis University in Chicago, where he teaches technology in education as well as he history and philosophy of education. Among Craig's specific research interests are the impact of Web 2.0 tools on learning in and out of school, the history of moral education in the United States, and John Dewey's theory of inquiry. He is a former chair of the Philosophical Studies of Education SIG of AERA and is incoming chair of the Dewey Studies SIG of AERA. Craig is currently working on a book about the teaching of systems thinking and modeling in K-12 classrooms. He can be reached at craig.cunningham@nl.edu.

Suzanne T. Gurland (sgurland@middlebury.edu) is Assistant Professor of Psychology at Middlebury College in Middlebury, Vermont. She studies the motivational underpinnings of children's relationships with their teachers and with other important adults in their lives.

Kalinda R. Jones, kalindaj@gmail.com, a former high school teacher and current school counselor, is presently a doctoral candidate in Counseling Psychology at Indiana State University. Her research interests involve teacher dispositions, urban education, implementation of research into classroom practice, and the integration of psychological theories into the training and professional development of teachers and school counselors. Her dissertation is titled Teacher Self-Efficacy Beliefs Related to Chronic Disruptive Behavior.

Shannon Lindsay Toth is a doctoral candidate in Curriculum and Education at Southern Illinois University. Her specialization is Curriculum Theory, with a specific interest in Social Justice curriculum development and implementation. Shannon teaches "Schooling in a Diverse Society" for pre-service teachers and has participated as a committee member for the Social Justice Leadership Institute at SIUC since its inception. 
(c) Copyright 2011. The authors, Deborah Seltzer-Kelly, Serina Cinnamon, Craig A Cunningham, Suzanne T. Gurland, Kalinda R. Jones, \& Shannon Lindsay Toth, assign to the University of Alberta and other educational and non-profit institutions a non-exclusive license to use this document for personal use and in courses of instruction provided that the article is used in full and this copyright statement is reproduced. The authors also grant a non-exclusive license to the University of Alberta to publish this document in full on the World Wide Web, and for the document to be published on mirrors on the World Wide Web. Any other usage is prohibited without the express permission of the authors. 